\title{
O aluno de pós-graduação stricto sensu no Brasil: revisão da literatura dos últimos 20 anos $^{1}$
}

\author{
The graduate student in Brazil: literature review from \\ the last 20 years
}

\section{Lo estudiante de posgrado en Brasil: revisión de la literatura de los últimos 20 años}

Talita Caetano Silva, mestre em Psicologia pela Universidade Federal de Santa Catarina (UFSC), Florianópolis, SC, Brasil. E-mail: tcsilvaa@gmail.com.

Marúcia Patta Bardagi, doutora em Psicologia pela Universidade Federal do Rio Grande do Sul (UFRGS) e professora adjunta do curso de Psicologia da Universidade Federal de Santa Catarina (UFSC), Florianópolis, SC, Brasil. E-mail: marucia.bardagi@gmail.com.

\section{Resumo}

O crescimento da pós-graduação no Brasil e a procura de pós-graduandos por intervenções de carreira ampliaram o interesse em se compreenderem as escolhas, as expectativas e as dificuldades desses estudantes. Esta revisão de literatura descreve os estudos brasileiros sobre os alunos de pós-graduação stricto sensu publicados nos últimos 20 anos para verificar os principais aspectos investigados sobre essa população. Por meio de pesquisas em bases de dados (SciELO, BDTD, Lilacs e BVS), foram identificadas e analisadas 35 publicações. Constatou-se que há concentração de publicações na área da Saúde, equilíbrio entre estudos qualitativos e quantitativos, além do foco na avaliação do aluno sobre os processos de ensino e aprendizagem na pós-graduação. Há necessidade de estudos que investiguem o desenvolvimento de carreiras e a adaptação acadêmica dos pósgraduandos. Ainda, devido à especificidade da formação, é preciso diversificar as áreas nas futuras investigações acerca do tema.

10 presente artigo faz parte da dissertação de mestrado da primeira autora, sob orientação da segunda. As autoras agradecem à Capes o auxílio recebido por meio de bolsa de mestrado concedida à primeira autora. 
Palavras-chave: Pós-Graduação. Carreira. Mestrado. Doutorado.

\section{Abstract}

The growth of graduate studies in Brazil and the increased demand of graduate students for career interventions amplified the interest in understanding the choices, expectations and difficulties of these students. This literature review describes studies published in the last 20 years focusing on graduate students in order to understand the main subjects investigated and also identify new areas for future research. After a search in databases (SCIELO, BDTD, LILACS and BVS), 35 identified publications were analyzed. There was a greater concentration of publications in the health field, a balance between qualitative and quantitative studies, and a main focus on students' evaluation of teaching and learning processes in graduate school. There is a need for studies to investigate the career development and academic adaptation of graduate students. Besides, due to course specificity, there is a need for a greater diversity of covered areas in future investigations.

Keywords: Graduate. Career. Masters. Doctorate.

\section{Resumen}

Lo crecimiento del posgrado en Brasil y el aumento de la demanda de los estudiantes de postgrado por las intervenciones de carrera aumentaran el interés en la comprensión de las opciones, las expectativas y dificultades de estos estudiantes. Esta revisión de la literatura identifico los estúdios publicados en los últimos 20 años centrados en los estudiantes de posgrado a fin de comprender los principales temas investigados y también identificar nuevas áreas para la investigación futura. Después de la busqueda en bases de datos (SCIELO, BDTD, LILACS y BVS), se analizaron las 35 publicaciones identificadas. Hay una mayor concentración de las publicaciones en la área de salud, un equilibrio entre los estudios cuantitativos y cualitativos, y la concentración principalmente en la evaluación de los alumnos de la 
enseñanza y el aprendizaje en la escuela de posgrado. Existe la necesidad de estudios para investigar el desarrollo de la carrera profesional y la adaptación académica de estudiantes de posgrado. Además, debido a la especificación de los cursos, hay una necesidad de una mayor diversidad de áreas cubiertas en las investigaciones futuras.

Palabras clave: Posgrado. Carrera. Maestría. Doctorado.

\section{Introdução}

A alta competitividade do mercado de trabalho contemporâneo e a precarização de muitos vínculos de trabalho têm afetado os jovens diplomados brasileiros. O diploma universitário parece já não garantir tantas vantagens no que se refere à busca por um emprego. Pimentel (2007) problematiza o fato de o número de empregos ser desproporcional ao número de recém-formados à procura de uma colocação profissional. Mattos (2011), por exemplo, constatou que, diante de um estreitamento percebido de oportunidades de trabalho, o alongamento da escolarização torna-se uma possivel escolha entre os jovens que estão prestes a finalizar seus cursos de graduação. De acordo com Pimentel (2007), para muitos jovens, poder dizer que estão estudando suaviza o impacto negativo de dizer que estão fora do mercado de trabalho. Silva (2010) também destaca que a condição para a efetivação de um emprego está fortemente associada à exigência por mais qualificação, ao mesmo tempo em que o mercado de trabalho é caracterizado por sua progressiva exclusão e ineficiência. Bardagi et al. (2006) afirmam que a insegurança dos estudantes em fase final de curso em face do enfrentamento do mercado de trabalho, bem como do exercício da atividade profissional, faz com que os alunos busquem recursos instrumentalizadores capazes de auxiliá-los na busca por um emprego. Entre esses recursos, a educação continuada (cursos de aperfeiçoamento, especialização e pós-graduação strictu sensu) é percebida como uma das principais opções.

Quanto à pós-graduação propriamente dita, Barbosa et al. (2009) destacam que nos últimos anos - desde 2000 - são cada vez mais jovens os alunos que a frequentam, o que indica que a opção de transição direta 
graduação / pós-graduação tem crescido. No estudo de Schillings (2005) com estudantes da área de Ciências Humanas da UFSC, 30,3\% dos 170 mestrandos tinham menos de 25 anos e 29,8\% tinham idades entre 26 e 30 anos, o que corresponde a 60,1\% da amostra. A possibilidade de recebimento de uma bolsa de estudos durante as atividades de mestrado e de doutorado pode também ser identificada como fator de decisão para a entrada dos alunos mais jovens na pós-graduação, especialmente no mestrado, de acordo com Mattos (2011).

É preciso ressaltar a acelerada expansão da pós-graduação, (também devida às políticas públicas voltadas ao ensino superior), que implicou a ampliação de programas de pós-graduação no Brasil, maior distribuição de bolsas de auxílio e alto índice de títulos de mestres e doutores. Os programas nacionais de pós-graduação titularam no ano de 1998 - primeiro ano registrado na Plataforma GeoCapes - 12.351 mestres e 3.915 doutores. Já no ano de 2004, há 11 anos, portanto, foram mais de 27.000 mestres e 9.000 doutores (GEOCAPES, 2015). No que se refere à distribuição de discentes de pós-graduação no Brasil, no ano de 2014 - último ano analisado pela Capes - foram 115.558 matrículas no mestrado acadêmico, com 44.502 titulações ao final do ano. 0 doutorado registrou 94.850 alunos matriculados e 16.745 titulações. Com referência à distribuição de instituições de ensino superior (IES) no Brasil, o ano de 2014 assinalou o total de 3.678 instituições, sendo que 1.199 disponibilizam cursos de mestrado acadêmico, 58 apenas doutorado, 1.896 mestrado e doutorado (ambos acadêmicos) e 525 com cursos de mestrado profissionalizante. Quanto à distribuição por áreas, em 2014, conforme classificação da Capes, 473 programas eram da área de Ciências Socias Aplicadas (12,8\%), 523 das Ciências Humanas $(14,2 \%), 187$ correspondiam à Linguística, Letras e Artes $(5,1 \%), 299$ à área de Ciências Exatas e da Terra (8,1\%), 286 programas eram de Ciências Biológicas (7,8\%), 549 da área Multidisciplinar (14,9\%), 389 de Ciências Agrárias (10,6\%), 586 de Ciências da Saúde (15,9\%) e 386 de Engenharias (10,6\%). Em relação às bolsas de estudo, em 2010 a GeoCapes registrou que no Brasil recebiam bolsas 33.357 mestrandos e 21.941 doutorandos. Em 2014, houve um acréscimo no número de bolsistas, que passou para 48.113 mestrandos e 39.954 doutorandos (GEOCAPES, 2015). 
Também com referência à expansão dos cursos de pós-graduação, Schwartzman (2010) sinaliza que é difícil obter uma identificação exata do número de alunos matriculados na pós-graduação como um todo no país, mas é possível saber que $54 \%$ dos alunos matriculados na modalidade lato sensu estão em instituições privadas, enquanto a pósgraduação strictu sensu, em sua maioria, se dá em instituições públicas. Schwartzman (2010) destaca ainda que a idade média dos estudantes nas duas modalidades é de 34 anos, que o rendimento familiar é médio alto e que em ambos os tipos de pós-graduação predomina o público feminino.

A literatura existente sobre pós-graduação é bastante vasta. No entanto, em sua maioria, os estudos concentram-se em discussões de políticas públicas de ensino superior, estrutura dos programas, implementação de cursos, mapeamento de índices de diplomação e avaliação de cursos, como se vê em Cirani, Silva e Campanário (2012); Kornis, Maia e Fortuna (2010); Oliveira e Siqueira (2013) e Tourinho e Palha (2014). Considerando-se as transformações da área, o aumento do interesse pelo desenvolvimento de carreira universitária (aspectos relativos à escolha dos cursos, projetos de vida, satisfação acadêmica, evasão) e o crescimento da população universitária e de pós-graduação entre os clientes da orientação profissional, percebe-se a necessidade de estudos que tenham interesse em compreender de que modo ocorrem as escolhas profissionais durante a pós-graduação, bem como conhecer as expectativas dos alunos para a entrada no mercado de trabalho, demarcando de modo mais explícito esse outro marco transitório da vida do sujeito. No caso do aumento do número de alunos de pós-graduação que procuram orientação de carreira, de acordo com Bonadiman et al. (2016), pós-graduandos são um público relativamente novo nos serviços de carreira, mas muitos mestrandos e doutorandos têm buscado auxílio para pensar seus projetos de futuro, para refletir sobre o papel de pesquisador e professor que a pós-graduação favorece e para pensar estratégias de enfrentamento de questões acadêmicas e relacionais com colegas e orientadores.

Assim, este artigo busca apresentar uma revisão da literatura nacional sobre pós-graduação strictu sensu, a fim de identificar o número 
e as características dos estudos cujo foco estivesse nos alunos pósgraduandos. Pretende-se, dessa forma, contribuir com um novo olhar sobre o conhecimento produzido acerca da pós-graduação, a partir da análise dos estudos sobre os discentes e seus resultados. Como afirmam Teixeira et al. (2007), poder acompanhar o desenvolvimento de uma área do conhecimento por meio da análise de sua produção científica possibilita reconhecer a importância de determinadas temáticas e apontar caminhos de crescimento de outras.

\section{Método}

De modo a ancorar a realização desta bibliometria, foram utilizados os indexadores Biblioteca Digital Brasileira de Teses e Dissertações (BDTD), que contém armazenadas teses e dissertações em âmbito nacional, e Biblioteca Virtual em Saúde (BVS), onde é possível ter contato com diferentes bases de dados, como o SciELO e a Lilacs, por exemplo. Optou-se por tais indexadores pelo fato de oferecerem uma variabilidade de áreas do conhecimento em suas buscas, além de serem bases especializadas em trabalhos científicos com texto completo. Selecionaram-se oito descritores isoladamente (pós-graduação, pósgraduando(s), mestrado, mestrando(s), doutorado, doutorando(s), aluno(s) de pós-graduação e estudante(s) de pós-graduação) e procedeuse à busca utilizando-se os descritores isolados ou em combinações. Essa etapa resultou na identificação de 666 resultados. Após a exclusão das repetições, dos trabalhos não disponibilizados em versão completa, dos estudos teóricos e dos estudos que não tinham o aluno como foco, foram totalizados 33 artigos produzidos, além de uma tese e de uma dissertação, resultando em um total de 35 produções.

Foram realizadas análises quantitativas dos dados, por meio de contagem de frequências, para a identificação do ano de publicação dos artigos, da metodologia utilizada e da área do conhecimento. Das nove grandes áreas (e suas respectivas subáreas) definidas pela Capes, os artigos encontrados nesta revisão representam apenas quatro grandes áreas - Ciências da Saúde (com trabalhos encontrados nas subáreas de Enfermagem, Medicina, Saúde, Nutrição e Educação Física), Ciências 
Humanas (com trabalhos encontrados nas subáreas de Educação, Psicologia e Geografia), Ciências Sociais e Aplicadas (com trabalhos encontrados na subárea de Administração) e Literatura, Letras e Artes (com trabalhos encontrados nas subáreas de Literatura e Linguística).

Após a leitura na íntegra dos 35 documentos encontrados, buscou-se ainda realizar uma categorização dos trabalhos a partir de temas gerais, sob uma ótica qualitativa, sendo as categorias definidas as seguintes: a) Avaliação do processo de ensino-aprendizagem e da formação na pós-graduação; b) Satisfação com a formação, bem-estar psicológico e dificuldades percebidas por pós-graduandos e egressos; c) Perfil dos alunos e aspectos ligados à posterior inserção profissional; e d) Razões para a escolha da pós-graduação e expectativas de futuro dos alunos.

\section{Resultados e discussão}

1) Análise quantitativa dos estudos - prevalência de áreas, produções por ano e temas frequentes

Ao analisar os anos em que os documentos foram produzidos, observa-se que, na primeira década, entre os anos de 1995 e 2005, foram obtidos poucos resultados, totalizando apenas seis trabalhos. O ano de 2005 registrou quatro trabalhos, e os anos de 1999 e 2002 contabilizaram um documento em cada um deles. No período de 2006 a 2015 houve crescimento no número de publicações, alcançando 29 produções, o que demonstra um aumento significativo do interesse por questões voltadas aos alunos pós-graduandos. No segundo período, ao contrário do primeiro, em todos os anos, houve ao menos um estudo sobre pós-graduação focalizando os alunos.

Considerando-se as grandes áreas e suas subáreas, observase que os trabalhos concentram-se nas Ciências da Saúde. São 15 documentos, distribuídos entre as subáreas de Enfermagem (5), Medicina (6), Saúde (2), Nutrição e Educação Física (cada um com uma publicação). Em seguida aparece a área de Ciências Humanas, totalizando 
12 publicações, distribuídas entre Psicologia (7), Geografia (1) e Educação (4), seguida da grande área das Ciências Sociais e Aplicadas, com sete trabalhos da área de Administração, e, por fim, a área de Linguística, Letras e Artes, com uma publicação. A maior concentração de estudos na área da Saúde acompanha a maior concentração de programas e alunos também na área. Segundo os registros da GeoCapes (2015), a maior porcentagem de programas distribuídos por área do conhecimento encontra-se na Saúde, sendo que dos 3.678 programas contabilizados no ano de 2014, 586 são da Saúde, correspondendo a aproximadamente 16\% da amostra total. É lógico afirmar que um número maior de programas $\mathrm{e}$, consequentemente, de alunos e de pesquisadores, resulta em um volume expressivo de produção. Ainda, pelas próprias características das subáreas envolvidas, as preocupações com temas de saúde, bem-estar e satisfação, entre outros, podem ter contribuído para o significativo número de publicações com foco nos estudantes.

Entretanto, apesar de a distribuição de programas de pósgraduação por área no país não ser equitativa, há necessidade de expansão e de diversificação de estudos a respeito da temática da pós-graduação, de modo a contemplar as especificidades das diferentes formações, visto que das nove grandes áreas do conhecimento preconizadas pela Capes, apenas quatro foram abrangidas no presente estudo.

Em relação ao método de pesquisa adotado pelos estudos mapeados, destaca-se que, das 35 publicações analisadas, 17 documentos utilizaram o método de abordagem qualitativa, 14 publicações tiveram abordagem quantitativa, e quatro produções optaram por abordagem mista, o que indica equilíbrio entre os dois tipos de metodologia de estudos. Como apontam Minayo e Sanches (1993), a abordagem quantitativa atua em niveis da realidade, em que os dados se apresentam aos sentidos, tem como objetivo trazer à luz dados, indicadores e tendências observáveis e deve ser utilizada para abarcar, do ponto de vista social, grandes aglomerados de dados, de conjuntos demográficos, por exemplo, classificando-os e tornandoos inteligíveis. Já a abordagem qualitativa trabalha com valores, crenças, representações, hábitos, atitudes e opiniões e tem como foco 
aprofundar a complexidade de fenômenos, fatos e processos particulares e específicos de grupos mais ou menos delimitados em extensão. Para as autoras, o estudo quantitativo pode gerar questões a serem aprofundadas qualitativamente, e vice-versa. Nesse sentido, percebese que as questões relativas ao aluno de pós-graduação estão sendo investigadas sob ambas as abordagens, de forma complementar.

A partir da leitura dos resumos dos objetivos explicitados nas publicações, foi feito um agrupamento por temas de estudo (a Figura 1 indica o número de publicações em cada tema). Percebe-se que o eixo temático de maior destaque foi "Avaliação do processo de ensino e aprendizagem e formação do pós-graduando”, com 19 publicações. Esse predomínio dos estudos de avaliação dos programas, especialmente pela ótica dos egressos, é coerente com a produção geral de conhecimento sobre a pós-graduação, centrada na avaliação e na discussão sobre a estrutura e as características dos programas. A categoria "Satisfação com a formação de pós-graduação" aparece como a segunda mais frequente neste estudo. Nota-se uma preocupação, principalmente em estudos das áreas de Saúde e de Ciências Humanas, com as questões relativas ao bem-estar psicológico dos pós-graduandos, relacionando índices de satisfação ou de sofrimento aos aspectos da experiência de pós-graduação. Mesmo que o número total de produções não seja alto para o período de tempo avaliado (20 anos), a concentração dos estudos em apenas quatro grandes temas indica que muito ainda pode ser feito em termos de ampliação das questões de pesquisa acerca da experiência dos alunos na pós-graduação. No âmbito dos próprios temas existentes, pode-se aumentar o número de estudos sobre questões ainda pouco representadas, como as razões da escolha pela pós-graduação e o levantamento do perfil dos estudantes. 


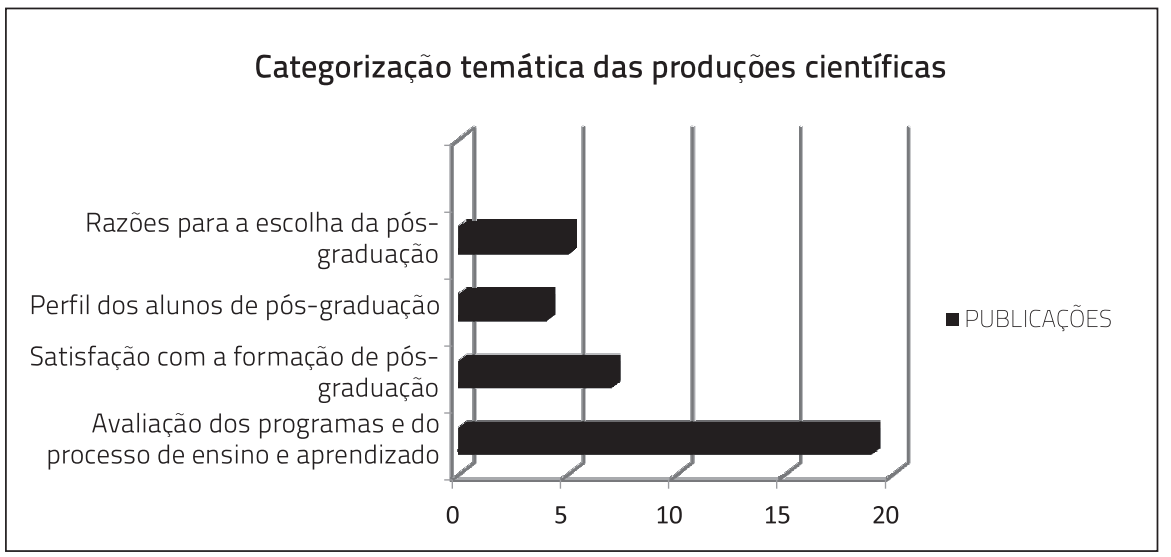

Figura 1. Categorização temática das produções científicas

Fonte: elaboração das autoras.

2) Análise qualitativa dos estudos: principais temas investigados e resultados obtidos

A seguir, apresenta-se o que cada documento encontrado e circunscrito exclusivamente em cada uma das quatro categorias buscou investigar e seus resultados.

a) Avaliação do processo de ensino e aprendizagem e formação do pósgraduando

A categoria "Avaliação do processo de ensino e aprendizagem e formação do pós-graduando contemplou 19 pesquisas, que foram realizadas com alunos regulares ou egressos, desde avaliações gerais sobre os programas, o corpo docente e as disciplinas oferecidas até avaliações mais detalhadas de atividades ou processos inerentes aos cursos, como a produção acadêmica docente e discente, o tempo de defesa, aspectos de internacionalização etc. Ainda que pudessem abarcar outros aspectos, como a satisfação pessoal com o curso ou questões de inserção profissional, o objetivo principal desses estudos estava no julgamento positivo ou negativo que os sujeitos faziam sobre os programas frequentados. No que diz respeito às exigências, é possivel citar os altos níveis de cobrança por produtividade, principalmente nos programas de pós-graduação stricto sensu. Mendes e lora (2014) 
tiveram o intuito de compreender as repercussões sentidas e percebidas provenientes das exigências de produtividade, sob a ótica dos pósgraduandos. Quase que com unanimidade, a delimitação do tempo e o manejo quantitativo dos altos índices de produção foram sentidos como os elementos que mais trouxeram dificuldades na formação do curso de mestrado.

Bujdoso (2009), em sua tese, buscou compreender a relação da inserção profissional com o mestrado nos cursos de Direito, Engenharia Civil e Medicina. Foram realizadas 24 entrevistas semiestruturadas, sendo 18- seis de cada área-com mestrandos e seis com orientadores. Os mestrandos da área médica diferenciaram-se daqueles da área do Direito e da Engenharia Civil pelo fato de serem um pouco mais velhos, por trabalharem e também por já terem escolhido a temática de estudo para dissertação, além de terem iniciado o desenvolvimento do projeto anteriormente ao ingresso no curso de mestrado. Como aspectos positivos, os mestrandos sinalizam que o mestrado oferece oportunidade de aprender e de participar da vida acadêmica, bem como fornece subsídios para a potencialização da autonomia. Entre os aspectos menos prazerosos, destacam as disciplinas, o exame de qualificação, o prazo, a falta de tempo, o acúmulo de tarefas, as renúncias impostas pelo mestrado, o baixo valor da bolsa de auxílio, a solidão e a carga emocional envolvida. Algo bastante comum entre os participantes das três áreas foi a preocupação quanto ao cumprimento do prazo, e a dificuldade de escrever foi citada por mestrandos de Engenharia Civil e de Medicina. No que diz respeito à carreira acadêmica, ainda de acordo com Bujdoso (2009), esse parece ser um motivo mais frequente entre os mestrandos de Direito, sendo que nenhum mestrando de Medicina apontou tal motivo. O principal motivo para cursar mestrado, como ressaltado pelos mestrandos e pelos orientadores, está relacionado ao suprimento de deficiências detectadas na graduação. No que tange à relação com os orientadores, de modo geral, esta se dava de maneira próxima e era de muito auxílio.

Sobre as nuanças do processo de formação, Ramos et al. (2010) investigaram de que modo ele ocorre, a partir da ótica dos egressos do programa de mestrado em Enfermagem de uma universidade pública. 
Sob uma perspectiva qualitativa, 88 egressos responderam acerca dos impactos que o mestrado trouxe para a formação e para a atuação profissional. Os participantes salientaram que é de fundamental importância o curso promover uma maior instrumentalização para o mercado de trabalho, pois partem do entendimento de que o profissional deve visualizar a realidade de modo amplo e inserir-se em tal realidade de maneira socialmente responsável. Também nessa direção, Souza et al. (2014) problematizam o campo científico da Alimentação e Nutrição, sob o olhar de 177 egressos de cursos de mestrado distribuídos nacionalmente. Os resultados mostram que, de modo geral, as expectativas dos então mestres foram alcançadas ou até mesmo superadas, uma vez que suscitaram o aprimoramento científico e uma boa qualificação docente. Entretanto, os participantes destacaram como dificuldades o pouco tempo para a conclusão do curso e a insuficiência no preparo para a docência. No que diz respeito ao mercado de trabalho, percebeu-se acréscimo na inserção de participantes em instituições públicas. Dos participantes que não estavam trabalhando, 75\% estavam realizando o doutorado. Ao serem questionados sobre possíveis mudanças na vida profissional após a conclusão do mestrado, eles afirmaram sentir maior autoconfiança, reconhecimento pelos pares e ascensão salarial. Souza et al. (2014) ainda enfatizam que, para muitos dos egressos, o mestrado não amplia conhecimentos da área de ensino e docência, sentindo que o curso vem perdendo a preocupação com a formação de profissionais para os campos do ensino e didático-pedagógico. Houve críticas também em relação ao estágio de docência: alegou-se que não existia um plano padronizado para realizar tais atividades, ficando sob a responsabilidade do aluno buscar a disciplina, o professor e o local de realização do estágio.

Assim como Souza et al. (2014) perceberam a fragilidade dos estágios de docência, Joaquim, Boas e Carrieri (2013) buscaram investigar de modo mais específico de que forma ocorre esse estágio, quais os sentidos atribuídos a ele e quais os impactos desse exercício sobre a formação. Os autores contaram com a participação de pós-graduandos do curso de Administração, em exercício de estágio de docência no ano de 2010 no estado de Minas Gerais. Os participantes do presente estudo ministraram no mínimo uma aula nos mais variados cursos de 
graduação. Percebeu-se, com certa unanimidade, falta de padronização no manejo e na execução do estágio, sendo essa uma das críticas mais recorrentes dos pós-graduandos. Alguns alunos ministraram mais aulas do que outros, por exemplo. A aproximação com a prática em sala de aula foi bastante mencionada como fator importante para a formação docente. Destacam-se o contato direto com os alunos, a potencialização da segurança diante dos graduandos em sala de aula e a oportunidade de desempenhar o papel de um professor, entre outros fatores. No entanto, ainda são citados sentimentos de insegurança e de despreparo, visto que o processo de treinamento - o estágio de docência, bem como a formação - não está oferecendo subsídios necessários que gerem reflexão sobre a formação docente. Ainda, foi possível perceber a necessidade de uma maior (re)integração entre a teoria e a prática nos processos de formação na pós-graduação.

No ano de 2012, Joaquim, Boas e Carrieri realizaram uma análise comparativa das práticas de estágio de docência em duas instituições uma pública e outra privada - de Minas Gerais. Nesse estudo, os autores discutem o fato de que os potenciais professores que assumiam sentir-se mais motivados demonstraram melhor desempenho. Tal motivação, de acordo com os autores, estava relacionada à obtenção de experiência em sala de aula e também ao sentimento de estar mais próximo ao campo da docência. Os participantes afirmaram que o exercício da docência estava para além de mera atividade profissional ou ainda curricular da formação, pois interpelava também as motivações pessoais de cada um. Um dado importante é a dificuldade que os pós-graduandos têm em aliar teoria e prática, e os participantes percebiam e compreendiam a importância dessa articulação. Assim, a falta de prática tornou-se, algumas vezes, limitante. A prática destacada pelos participantes vincula-se ao manejo de ministrar aulas e também à vivência do mercado. Os autores enfatizam que trazer outras possibilidades de realizar a prática - laboratórios de aprendizagem - ainda no momento de formação é de suma importância, pois isso oferece mais subsídios aos futuros docentes, deixando-os mais completos e preparados para o exercício profissional não tão distante.

Moreira e Tojal (2013), a partir da ótica de egressos da pósgraduação em Educação Física, objetivaram investigar as prioridades 
do processo de formação estabelecidas pela instituição. Para isso, os autores aplicaram questionário aos egressos no período de 2001 a 2006. Como um dos principais resultados, considerou-se que os programas de pós-graduação em Educação Física devem dedicar-se mais aprofundadamente ao processo de formação de futuros professores que exercerão seus respectivos papéis no nivel superior. Andere e Araújo (2008) também tiveram o intuito de avaliar a formação de professores de Contabilidade com base na análise dos programas de pós-graduação, contemplando quatro dimensões: a prática, a técnico-científica, a pedagógica e a social e política. As autoras contaram com a participação dos coordenadores da pós-graduação da área contábil e dos próprios alunos. Os resultados apontaram que os programas estão orientados para a formação de pesquisadores com enfoque teórico, específico e científico da área contábil, além de um direcionamento para a formação pedagógica, o que preconizam a docência e a prospecção de habilidades didáticas e pedagógicas. Sob a ótica dos alunos, os programas incentivam a formação prática, social e política, necessariamente nesta ordem. No entanto, para os coordenadores a formação prática é a menos incentivada no programa.

Também com o objetivo de compreender os processos de formação, Pardo e Colnago (2013) buscaram analisar de que modo os alunos de dois cursos de mestrado em Educação avaliam sua formação em pesquisa na graduação e na pós-graduação. Participaram do estudo 28 alunos do segundo ano do mestrado de ambos os cursos, sendo 10 do curso A e 18 do curso B. Os resultados indicaram que os cursos apresentavam-se muito diferentes no que se refere ao perfil esperado de mestrado e também aos parâmetros propostos pelas agências regulamentadoras - número de bolsistas e dedicação exclusiva ao curso, entre outros pontos. Um dos cursos aproximava-se muito mais desse perfil do que o outro, o que para os autores pode se relacionar com a avaliação geral feita pelos alunos sobre a formação e as consequências em termos de carreira e empregabilidade.

Ribeiro e Cunha (2010) investigaram as representações de alunos, egressos e professores de um curso de mestrado em Saúde Coletiva sobre a docência. De modo geral, constatou-se que a motivação 
dos participantes para ingressar na pós-graduação se deu pelo desejo de tornar-se docente do ensino superior, além de ampliar conhecimentos em pesquisas e de aprofundar saberes, desenvolvendo competências técnicas, políticas e sociais. No entanto, mesmo que os participantes tivessem a docência como uma expectativa profissional, poucos se sentem satisfeitos com as propostas curriculares do curso, alegando que há discrepância entre as expectativas inicialmente lançadas e a proposta de formação. Ainda como resultado, destaca-se que, apesar de haver fragilidade em relação ao preparo para a docência, os participantes puderam ampliar seus conhecimentos gerais e específicos, bem como sua capacidade crítica, o que contribui diretamente para a formação pessoal e profissional. As autoras observam que o desafio impelido aos programas é o de superar o modelo que contempla unicamente a competência da pesquisa na formação, incluindo preocupações pedagógicas, em especial a docência, que é um dos propósitos da pósgraduação.

A relação orientador-orientando também possui papel fundamental na constituição do processo de formação. Com o intuito de compreender as influências que essa relação causa na elaboração de teses e dissertações, Leite Filho e Martins (2006) investigaram programas de pós-graduação stricto sensu em Contabilidade na cidade de São Paulo. Os achados de pesquisa indicam que os orientadores, ao escolherem seus orientandos, valorizam atributos técnicos, enquanto os orientandos, ao escolherem seus orientadores, valorizam atributos afetivos e pessoais. Os autores ainda destacam que os encontros de orientação tendem a ser assistemáticos, por vezes em clima de autocracia, e alegam que essas reuniões não provocam efeitos significativos na qualidade do trabalho. Ainda nesse sentido, mesmo quando há uma estruturação, tais reuniões ainda carecem de maior sistematização. Esse dado, segundo os autores, gera insegurança, angústia e sentimento de solidão. Percebe-se a falta de direcionamento e de encontros com mais frequência por parte dos orientadores. Nesse estudo, os orientandos também revelam sentir-se pressionados a concluir seu curso e apresentam dificuldades quanto às expectativas sobre o manuscrito da dissertação ou da tese. De modo geral, Leite Filho e Martins (2006) perceberam que muitas das dificuldades sentidas 
no processo de construção do trabalho relacionam-se diretamente à ligação orientador-orientando. Ainda quanto ao papel da orientação, o estudo de Brock et al. (2010) detecta que, durante o mestrado, $72 \%$ dos participantes responderam que a relação com o orientador foi estimulante, $26 \%$ afirmaram que foi adequada e apenas $1,3 \%$ classificou como sendo inadequada. No que se refere à frequência de reuniões entre aluno e orientador, $72 \%$ sinalizaram que estas foram suficientes. Quando perguntados a respeito das dificuldades encontradas, apenas $4,8 \%$ apontaram ter tido dificuldades com o orientador. Já com relação ao doutorado, 78,8\% responderam que a orientação foi estimulante e apenas $1,9 \%$ respondeu que a orientação foi inadequada.

Villard e Vergara (2011) realizaram um estudo exploratório com o propósito de avaliar o ensino-aprendizagem, acompanhando, durante e após, o processo de aprender a ser pesquisador. As autoras buscaram responder a "como mestrandos aprendem, por meio de prática experiencial, a realizar a pesquisa qualitativa em Administração?”. Villard e Vergara (2011) concluíram que a pesquisa de campo e a prática de reflexão sobre e no campo trouxeram impactos significativos, ampliando a consciência dos participantes acerca do processo de ensinoaprendizagem. Na mesma linha, Depes e Pereira (2013) realizaram um estudo sob a abordagem qualitativa exploratória com nove egressos mestres - de um programa de pós-graduação em Enfermagem do Mato Grosso. As autoras tinham como intuito compreender de que modo o processo de formação contribuiu na mobilização de conhecimentos científicos. Os dados indicaram, na opinião das autoras, que os participantes, atuantes em serviços de saúde, sentem-se preparados para intervir em seu espaço de trabalho a partir do manejo dos saberes científico, político e ético, os quais foram preconizados, refinados e aprofundados na formação do mestrado.

Alencar (2002) realizou um estudo com 92 pós-graduandos com o intuito de compreender de que forma acontece o estímulo à criatividade em programas de pós-graduação. Os resultados mostram que as condições que favorecem a criatividade durante o processo de formação devem estar relacionadas aos próprios objetivos da pós-graduação. A pós-graduação tem a incumbência de produzir novos conhecimentos, 
destacando-se social e cientificamente. Tendo em vista esse propósito - estímulo ao novo conhecimento -, os programas de pós-graduação devem potencializar a criatividade e a inovação.

Mendes et al. (2015) produziram um estudo histórico-social em uma escola de Enfermagem entre os anos de 1972 e 1975. A partir de análise documental e de entrevistas com ex-alunos e ex-professores da época, buscaram investigar o curso de mestrado, analisando a sua estrutura, o currículo e as disciplinas preconizadas. Identificaram que o curso era composto por um corpo docente capacitado no exterior, que o currículo aliava experiências teóricas e práticas e direcionava para a formação didática e pedagógica. No entanto, foi citada a falta de docentes qualificados para lecionar e também a ausência de disciplinas que promovessem a formação crítica e reflexiva. Canhada e Bulgacov (2011) trouxeram em seu estudo uma análise do programa de doutorado em Administração de duas universidades públicas, buscando identificar as práticas sociais que balizam os resultados acadêmicos. Pontuamse como principais resultados o comprometimento e a dedicação dos doutorandos, a valorização da pesquisa e a proximidade com o mundo das organizações por parte dos docentes, devido à peculiaridade da área pesquisada.

Trabalhos com enfoque na avaliação de disciplinas específicas, como o de Freitas e Seiffert (2007), que examinam a disciplina de formação didático-pedagógica em Saúde do programa de pós-graduação da Unifesp, e trabalhos em que os alunos avaliam as competências docentes, como o de Grohmann e Ramos (2012) com alunos de mestrado em Administração, também compuseram esta categoria. Percebe-se uma divisão entre estudos de caráter mais geral, cujas avaliações da formação são feitas de forma mais genérica pelos alunos, incluindo a percepção de impacto da pós-graduação sobre o crescimento pessoal e profissional, o conhecimento e a prática profissional e docente, e avaliações mais pontuais que focalizam atividades específicas da pósgraduação e como elas são percebidas pelos alunos. Considera-se que, não obstante a importância de avaliações gerais, a investigação sobre temas específicos pode ser bastante útil como feedback para os programas de mestrado e de doutorado e permitir ajustes necessários e a potencialização de resultados positivos. 
Nesse sentido, sintetizando os estudos revisados nessa categoria, as questões apontadas pelos estudos sobre a formação para a docência - o estágio docência em particular - e a relação orientadororientando parecem fornecer importantes subsídios para reflexão e para novas linhas de investigação. Por exemplo, o tema do estágio docência, atividade presente em praticamente todos os programas de pós-graduação, já parece ser um tópico temático de forte interesse, e os resultados dos estudos aqui descritos indicam forte descontentamento por parte dos alunos com essa prática, além de pouca organização dos programas quanto à sua implementação. De forma que o tema mostrase um importante ponto para as investigações futuras na área da pósgraduação, tanto em termos do seu funcionamento e objetivos quanto de sua eficácia para a formação. Ainda, outras atividades próprias dos programas de pós-graduação poderiam também ser analisadas, como as atividades de defesa de projeto / qualificação e a participação em eventos, entre outros. Além dos estágios de docência, a relação orientadororientando, também de fundamental importância, aparece ainda pouco como tema de estudos. Os resultados de Leite Filho e Martins (2006) oferecem um panorama de certa forma preocupante das diferenças entre as expectativas e os sentimentos de alunos e professores sobre essa relação, o que acena para a necessidade de maior exploração dessas diferenças e suas consequências em futuros estudos.

b) Satisfação com a formação, bem-estar psicológico e dificuldades percebidas por pós-graduandos e egressos

Os estudos apresentados nesta categoria têm como foco principal descrever aspectos de satisfação de alunos ou egressos com a formação na pós-graduação, bem como avaliar as principais dificuldades e fontes de sofrimento percebidas por eles. Por exemplo, Hortale et al. (2014) mostram a trajetória e a satisfação profissional de egressos de cursos de doutorado na área da Saúde, contando com a participação de 827 egressos distribuídos entre os anos de 1984 e 2007. Nos resultados, os autores perceberam que os índices mais altos de satisfação ocorreram para as variáveis "relevância social do trabalho", "oportunidade de novas aprendizagens e exercícios de criatividade" 
e "oportunidade de desenvolvimento profissional", e o menor índice foi para a variável "remuneração". Apesar da insatisfação quanto à remuneração, os participantes se sentiam satisfeitos com a relevância e o impacto social do seu trabalho e com as oportunidades de criatividade e inovação. Os processos acadêmicos também foram avaliados pelos acadêmicos, sendo positivas as avaliações quanto ao processo seletivo, e negativas as avaliações quanto às estratégias de avaliação dos docentes e das disciplinas. Para Hortale et al. (2014), ainda há falta de dados quando o assunto é egressos de programas da pós-graduação, pois nem mesmo o Plano Nacional de Pós-Graduação (PNPG) faz referência ao acompanhamento dos já titulados. Isso permitiria uma análise mais minuciosa dos efeitos da formação na trajetória profissional, além de possibilitar subsídios para possíveis ajustes nos processos de formação e curriculares.

As fontes de estresse têm sido bastante avaliadas, o que indica preocupação com a saúde mental e o bem-estar dos alunos. Com o objetivo de identificar os fatores de estresse e as estratégias de coping, Bujdoso e Cohn (2008) realizaram estudo com alunos de mestrado do curso de Enfermagem. Pôde-se perceber que o mestrado é um espaço de legitimação do saber e do trabalho intelectual. Entretanto, a dificuldade de conciliar ensino e pesquisa, teoria e prática e ensino e assistência destacou-se nas falas dos participantes como grande geradora de obstáculos. Na pesquisa realizada por Faro (2013), contando com a participação de 2.157 acadêmicos de mais de 100 programas de pósgraduação, alocados nas cinco regiões do Brasil e contemplando as nove grandes áreas do conhecimento classificadas pela Capes, distribuídos em 66 instituições, a exigência acadêmico-produtiva evoca queixas que se transformam em estressores, como, por exemplo, falta de tempo para conciliar os estudos com a vida pessoal e incertezas no que se refere à inserção profissional após o término da pós-graduação, entre outros aspectos. Os autores Santos e Alves Junior (2007) buscaram conhecer a ocorrência de estresse em 27 alunos - 16 mulheres e 11 homens - de mestrado de um programa de Ciências da Saúde. Entre os principais resultados, destaca-se o fato de que $40,7 \%$ dos participantes apresentavam estresse, sendo as mulheres as mais vulneráveis. 
Novaes Malagris et al. (2009) avaliaram também a presença de estresse em alunos pós-graduandos. Os autores contaram com a participação de 140 alunos distribuídos nos mais diversos centros universitários, sendo 74 mulheres e 66 homens com idade média de 30 anos. Percebeu-se um índice de estresse mais elevado no centro de Ciências da Matemática e da Natureza $(82,4 \%)$, seguido do centro tecnológico (61\%), do fórum de Ciência e Cultura (60\%), do centro de Letras e Artes e centro de Filosofia e Ciências Humanas (55\%), do centro de Ciências Jurídicas e Econômicas e do centro de Ciências da Saúde (50\%). Os autores destacam que o nível de estresse encontrado nos alunos foi relativamente alto, o que gera preocupações significativas, e sugerem estudos que enfoquem os motivos estressores específicos de cada área do conhecimento.

Louzada e Silva Filho (2005) investigaram as relações existentes entre a formação de pesquisador e os possiveis sofrimentos psíquicos decorrentes desse processo. Os autores contaram com a participação de 21 estudantes da área biomédica. Os dados revelaram que o sofrimento psíquico é inerente ao percurso acadêmico e que surge de diferentes formas e com diferentes intensidades. Destacam-se como principais dificuldades as institucionais, como a dificuldade de financiamento; a condução do projeto de pesquisa, a divulgação e publicação de trabalho e o próprio processo de tornar-se pesquisador "independente”.

Os estudos revisados nesta categoria, além de alguns resultados presentes na categoria anterior, permitem identificar que a maior parte dos alunos avaliados indica estar satisfeita com a formação concluída ou em andamento. Apesar disso, são vários os fatores geradores de ansiedade e, inclusive, de sofrimento psicológico presentes na experiência de pós-graduação. Esses fatores são tanto pessoais (dificuldades de manejo do tempo, por exemplo) quanto contextuais e de estrutura dos programas (como exigências de produtividade e pouco acompanhamento por parte do orientador). Nesse sentido, os resultados apresentam um contexto de potencial fragilidade e de vulnerabilidade dos alunos, o que pode resultar em desengajamento acadêmico ou mesmo abandono dos programas. É preciso que as coordenações de cursos de pósgraduação atentem para as condições psicológicas e para os recursos 
de enfrentamento dos alunos e possam oferecer espaços e serviços de apoio que minimizem as experiências negativas. Exemplos de estratégias favorecedoras são uma maior aproximação entre os corpos docentes e discentes, a realização de reuniões periódicas de avaliação e a oferta de serviços de mentoria e aconselhamento aos alunos, estratégias que já se mostraram benéficas para os alunos da graduação universitária, como ressaltam Frison (2012) e Gomes-Callado (2012).

c) Perfil dos alunos e aspectos ligados à posterior inserção profissional

Zaidan et al. (2011) se propuseram a analisar as repercussões da pós-graduação na carreira profissional de 305 egressos de um programa em educação, no período de 1977 a 2006. Os autores constataram que lecionar no ensino superior é a ocupação da maioria dos egressos. Perceberam também que os doutores se concentram na academia e em pesquisas, e os mestres se distribuem nas IES, na educação básica e em atividades de cunho autônomo. Os mestres e doutores entrevistados avaliaram positivamente a formação em pesquisa, considerando a pós-graduação um local de formação em pesquisa e de produção de conhecimento. Ortigoza, Poltroniéri e Machado (2012) investigaram a atuação profissional de ex-alunos de um programa de pós-graduação em Geografia entre 1980 e 2008 como uma dimensão no processo de avaliação, abrangendo a qualidade da formação e o preparo de profissionais de alto nivel para o mercado de trabalho. O levantamento das autoras possibilitou retomar 31 anos de formação de mestrado e 25 anos de doutorado. Constatou-se que, em sua maioria, os participantes estavam trabalhando ou já aposentados, atuavam em IES pública ou privadas; $68 \%$ dos mestres e $89 \%$ dos doutores estavam distribuídos em todas as regiões do país realizando contribuições científicas e sociais.

Gomes e Goldemberg (2010) realizaram uma avaliação da pósgraduação em Saúde Coletiva sob a ótica de egressos situados no período de 1998 a 2007. As autoras realizaram uma investigação a respeito do papel da pós-graduação no trajeto intelectual e profissional dos egressos, objetivando caracterizar a formação dos participantes. Como principais resultados, destacam-se o gênero feminino, o rejuvenescimento dos 
pós-graduandos e a diminuição do tempo de titulação. Se, por um lado, a escolha por um curso de graduação é atribuída à "vocação" sentida no instante do vestibular, por outro, pode-se afirmar que a escolha por um curso de pós-graduação está permeada pelas possibilidades de especialização, pelas pesquisas decorrentes da graduação e, nitidamente, pelas oportunidades oferecidas e vislumbradas no mercado de trabalho. Estevam e Guimarães (2011) mapearam os perfis de 39 egressos titulados de um programa de pós-graduação, buscando salientar o impacto que o programa Ihes trouxe para a formação docente e de pesquisador. Dessa amostra, 31 participantes eram mulheres, e a maioria dos ex-alunos realizou a graduação em instituição pública. Entre as razões que levaram os participantes a optarem pela pós, destaca-se a busca da carreira docente e de pesquisador. A maioria dos sujeitos orienta trabalhos e atua em instituições públicas. Quando perguntado aos participantes se escolheriam a mesma profissão, área e orientador, a grande maioria respondeu afirmativamente. Os autores declaram que o receio de ser excluído do mercado fez com que os participantes buscassem um aperfeiçoamento acadêmico, uma vez que o conhecimento e o saber são atributos valorizados socialmente.

Em síntese, nesses estudos os resultados apontam índices altos de inserção profissional dos alunos de pós-graduação em IES, particularmente dos egressos de doutorado, o que vai ao encontro das expectativas dos programas, das agências de fomento e do governo. As informações sobre perfil de alunos corroboram os dados de Schwartzman (2010) e de Schillings (2005) sobre o aumento do público feminino e a diminuição da idade média dos pós-graduandos no Brasil. Esse perfil indica que uma boa parte dos alunos faz a transição direta da graduação para a pós-graduação, sem, muitas vezes, a experiência e o contato com a realidade profissional das áreas.

d) Razões para a escolha da pós-graduação e expectativas de futuro dos alunos

Esta categoria temática contemplou os trabalhos que se concentraram nos motivos que levaram à escolha da pós-graduação e 
nas expectativas pessoais e de carreira dos alunos. Embora tais questões tenham aparecido de forma complementar em estudos das categorias anteriores, aqui estavam como tema central das pesquisas.

Barbosa et al. (2009) realizaram um estudo quantitativo que contou com 148 participantes egressos da pós-graduação do curso de Medicina, com idades entre 29 e 67 anos, sendo a maior parte da amostra constituída por mestres. 0 foco do estudo circunscreveu-se a avaliar as expectativas, o destino profissional e a produção científica de cada sujeito. Dos fatores que motivaram a escolha pela pós-graduação, o "aprimoramento técnico-científico" obteve o maior índice, com 39\%, seguido da opção "evolução na carreira de docente", com 28,8\%. Após o término do curso, 33,3\% apontaram que houve um aumento na confiança no desempenho de suas funções, $19,77 \%$ destacaram a melhor remuneração, 18,22 \% ressaltaram um maior conhecimento técnico e $17,83 \%$ sinalizaram que finalizar o curso Ihes proporcionou a obtenção de novo emprego. Além disso, 19,2\% elegeram como motivo da escolha pela pós-graduação a satisfação pessoal, $8 \%$ a reciclagem de conhecimentos e 6,9\% a melhor remuneração. Os autores chamam a atenção para o fato de que boa parte dos alunos, de modo equivocado, busca os cursos de mestrado e doutorado na tentativa de se aprimorar e de obter títulos, por vezes sem interesse pelas práticas de docência e pesquisa.

De acordo com Ferreira e Loureiro (2013), conhecer os motivos da busca pelo mestrado é uma tarefa importante para as instituições de ensino superior, pois permite interpretar a procura dos cursos e as expectativas dos seus estudantes. Em seu estudo, as autoras usaram como ponto de partida os seguintes questionamentos: que motivos influenciam os enfermeiros para a procura de mestrados? Que razões os levaram a escolher a instituição em que cursam o mestrado? A amostra contou com a participação de 39 enfermeiros, de idades entre 22 e 52 anos, sendo $79,48 \%$ do sexo feminino, frequentadores do curso nos anos de 2011 e 2012. Entre as razões para a escolha, as autoras destacam três grandes categorias: a necessidade de formação, a perspectiva de progressão na carreira e a motivação pessoal. Secaf e Kurcgant (1999), também pesquisando alunos da Enfermagem, avaliaram os motivos pelos quais doutores/doutorandos optaram por não realizar o mestrado 
na área de conhecimento em que se formaram na graduação. Os autores constataram que a não harmonia entre a demanda e a oferta de cursos faz com que profissionais optem por cursarem mestrados em outras áreas que não se configuram como cursos de pós-graduação em Enfermagem. De modo geral, o mestrado foi realizado na área da Educação, para muitos dos participantes uma escolha que facilitava a atuação como docente. É preciso considerar que tal busca por formação em áreas diferentes pode se dar pelo interesse dos indivíduos em se especializar em áreas novas, à procura de um saber multidisciplinar.

Rego et al. (2005), por sua vez, objetivaram relacionar os motivos de sucesso no que se refere à remuneração e investigar os perfis motivacionais de estudantes graduandos e pós-graduandos, bem como suas semelhanças e divergências. Também buscaram identificar se o perfil encontrado nesse trabalho se assemelha com as amostras portuguesas já consolidadas em que prepondera a motivação afiliativa. Os autores contaram com a participação de 594 estudantes, sendo 314 mestrandos e 280 bacharéis ou licenciados. Os mestrandos revelaram orientações mais elevadas para sucesso e poder, se comparados aos restantes. Além disso, perceberam que a remuneração tem relação positiva e direta com o motivo poder. Por fim, perceberam que, diferentemente dos achados no estudo português, os estudantes brasileiros demonstraram nível de motivação para o sucesso muito mais alto.

Louzada e Silva Filho (2005) investigaram a relação entre pósgraduação e a possivel inserção no trabalho. A partir de observação participante e entrevistas, contaram com a participação de um grupo de 12 doutorandos da área de Ciências da Saúde. Os resultados demonstraram que os doutorandos, em sua maioria, revelam preocupações quanto à futura inserção no trabalho. Além disso, referiram o interesse em trabalhar em universidades públicas. Como expectativas futuras, os doutorandos levantaram a possibilidade de realizar pós-doutorado ou projetos de pesquisa em colaboração, como forma de manter as bolsas de instituições de fomento, e também buscarem trabalhos de contratos temporários.

Nesta categoria alguns resultados são bastante interessantes em termos de sua consequência para a compreensão da experiência dos 
alunos de pós-graduação e para a compreensão dos demais estudos presentes nas categorias anteriores. Embora não muito numerosos, os estudos sobre os motivos de busca pela pós-graduação trazem informações que vão ao encontro dos achados de Mattos (2011), Pimentel (2007), Silva (2010) e Bardagi et al. (2006), entre outros, de que, diante do estreitamento de oportunidades de trabalho e das exigências por mais qualificação, o alongamento da escolarização torna-se uma possivel escolha entre os jovens que estão prestes a finalizar seu curso de graduação. A procura pela pós-graduação torna-se a busca por uma maior especialização, por mais tempo de "moratória”, por um currículo mais competitivo, por uma possibilidade de remuneração, e não necessariamente uma escolha de carreira com vistas a uma formação docente e de pesquisa. Nesse descompasso podem estar as razões da insatisfação com os cursos e programas apontados na primeira categoria de estudos, e a solicitação de maior aproximação entre pesquisa e prática, por exemplo. Conhecer melhor as características dos alunos, seus objetivos pessoais e de carreira torna-se fundamental, portanto, sendo uma direção importante para os estudos futuros na área da pós-graduação.

\section{Considerações finais}

Avaliar a qualidade dos níveis de ensino, incluindo cursos de mestrado e de doutorado, bem como a relação existente desses eixos da educação com o mundo profissional, tem sido pauta da agenda de instituições de ensino superior, como ressaltado por Barbosa et al. (2009). Países com nível alto de desenvolvimento social e econômico preocupam-se com a qualidade dos cursos de pós-graduação e com a escolha do indivíduo quanto à carreira de pesquisador. Nesse sentido, concorda-se com Hortale et al. (2014), que levantam uma crítica ao Brasil ao dizerem que estudos sistemáticos que visem ao acompanhamento da formação de pós-graduandos não são comumente realizados.

O aumento do número de cursos e de alunos de mestrado e doutorado no país nos últimos anos, de acordo com dados da GeoCapes de 2015, cria também uma necessidade maior de conhecimento sobre 
como ocorre a formação, como se estabelecem as relações entre os diferentes agentes envolvidos (alunos, professores, staff universitário, agências de fomento etc.) e quais os impactos da pós-graduação, tanto pessoais como sociais e institucionais. Este levantamento mostra, inicialmente, que, no conjunto dos estudos realizados sobre pósgraduação no Brasil, apenas uma parcela ínfima tem o aluno como foco (somente 35 produções). É claro que esse levantamento pode ter, pela escolha das bases de dados, do período temporal e de eventuais falhas na busca, deixado de identificar algumas produções relevantes ao tema. De qualquer maneira, ampliar esses estudos para que se possa conhecer as semelhanças e também as particularidades dos grupos de alunos já se torna um primeiro passo importante para futuras pesquisas. As realidades de mestrandos e doutorandos são diferentes, as realidades das áreas de formação são bastante distintas e também o são as realidades das instituições públicas e privadas. Estudos que contemplem essas vicissitudes permitirão identificar melhor os aspectos transversais e específicos da experiência de pós-graduação.

Ainda, com base nos resultados obtidos neste levantamento, alguns pontos de interesse já discutidos parecem constituir uma agenda de investigação que forneceria subsídios importantes para os cursos de pós-graduação, como a avaliação específica do impacto das atividades acadêmicas (a exemplo do estágio docência), a relação entre alunos e professores, em especial a relação aluno-orientador, a avaliação dos motivos de escolha pela pós-graduação e as expectativas de carreira dos alunos pós-graduandos. É preciso que os estudos diversifiquem os focos de interesse para além dos índices de produtividade e de inserção de egressos, sem desmerecer a importância desses índices, buscando descrever outros aspectos da realidade da pós-graduação.

Recebido em 23/11/2015

Aprovado em 16/02/2016 


\section{Referências}

ALENCAR, E. M. L. S. de. O estímulo à criatividade em programas de pós-graduação segundo seus estudantes. Psicologia: Reflexão e Crítica, Porto Alegre, v. 15, n. 1, p. 63-70, 2002.

ANDERE, M. A.; ARAUJO, A. M. P. de. Aspectos da formação do professor de ensino superior de ciências contábeis: uma análise dos programas de pós-graduação. Revista Contabilidade \& Finanças, São Paulo, v. 19, n. 48, p. 91-102, 2008.

BARBOSA, D. M. de M. et al. Análise do perfil dos egressos do Programa de Pós-Graduação em Medicina (Radiologia) da Faculdade de Medicina da Universidade Federal do Rio de Janeiro. Radiologia Brasileira, São Paulo, v. 42, n. 2, p.121-124, 2009.

BARDAGI, M. et al. Escolha profissional e inserção no mercado de trabalho: percepções de estudantes formandos. Psicologia Escolar e Educacional, Campinas, v. 10, n. 1, p. 69-82, 2006.

BONADIMAN, M. et al. Perfil dos usuários do LIOP - Laboratório de Informação e Orientação Profissional da UFSC: Mudanças percebidas nos últimos três anos. Caminho Aberto: Revista de Extensão do IFSC, Florianópolis, v. 2, n. 3., 2016. No prelo.

BROCK, L. et al. Alunos de um programa de pós-graduação em cardiologia: são os resultados de quase 30 anos adequados? Arquivos Brasileiros de Cardiologia, São Paulo, v. 94, n. 4, p. 500-506, 2010.

BUJDOSO, Y. L. V. Pós-graduação stricto sensu: busca de qualificação profissional ou suporte frente às vicissitudes do mundo do trabalho. Tese (Doutorado em Medicina)- Faculdade de Medicina, Universidade de São Paulo, São Paulo, 2009.

BUJDOSO, Y. L. V.; COHN, A. Universidade como coping para lidar com o trabalho na assistência do mestrando enfermeiro. Revista de Saúde Pública, São Paulo, v. 42, n. 2, p. 273-278, 2008. 
CANHADA, D. I. D.; BULGACOV, S. Práticas sociais estratégicas e resultados acadêmicos: o doutorado em administração na USP e na UFRGS. Revista de Administração Pública, Rio de Janeiro, v. 45, n. 1, p. 7-32, 2011.

CIRANI, C. B. S.; SILVA, H. H. M. da; CAMPANARIO, M. de A. A evolução do ensino da pós-graduação estrito senso em administração no Brasil. Revista de Administração Contemporânea, Curitiba, v. 16, n. 6, p. 765-805, 2012.

DEPES, V. B. S.; PEREIRA, W. R. Mobilização do conhecimento científico por egressos de um mestrado em enfermagem. Revista Gaúcha de Enfermagem, Porto Alegre, v. 34, n. 4, p. 84-90, 2013.

ESTEVAM, H. M.; GUIMARÃES, S. Avaliação do perfil de egressos do programa de pós-graduação stricto sensu em educação da UFU: impacto na formação docente e de pesquisador (2004-2009). Avaliação, Campinas, v. 16, n. 3, p. 703-730, 2011.

FARO, A. Um modelo explicativo para o bem-estar subjetivo: estudo com mestrandos e doutorandos no Brasil. Psicologia: Reflexão e Crítica, Porto Alegre, v. 26, n. 4, p. 654-662, 2013.

FERREIRA, M. F.; LOUREIRO, C. Motivos para a procura de mestrados: estudo exploratório com enfermeiros. Revista de Enfermagem Referência, Coimbra, v. 3, n. 9, p. 67-74, 2013.

FREITAS, M. A. de O.; SEIFFERT, O. M. L. B. Formação docente e o ensino de Pós-Graduação em Saúde: uma experiência na UNIFESP. Revista Brasileira de Enfermagem, Brasília, v. 60, n. 6, p. 635-640, 2007.

FRISON, L. M. B. Tutoria entre estudantes: uma proposta de trabalho que prioriza a aprendizagem. Revista Portuguesa de Educação, Braga, v. 25, n. 1, p. 217-240, 2012.

COORDENAÇÃO DE APERFEIÇOAMENTO DE PESSOAL DE NIVVEL SUPERIOR CAPES. GeoCapes. Disponivel em: <http://geocapes.capes. gov.br/geocapesds/>. Acesso em: 18 jun. 2015. 
GOMES, M. H. de A.; GOLDENBERG, P. Retrato quase sem retoques dos egressos dos programas de pós-graduação em Saúde Coletiva, 19982007. Ciência \& Saúde Coletiva, Rio de Janeiro, v. 15, n. 4, p. 1.989-2.005, 2010.

GOMEZ-COLLADO, M. E. La percepcion de los estudiantes sobre el Programa de Tutoria Academica. Convergencia: Revista de Ciencias Sociales, Toluca, v. 58, p. 209-233, 2012.

GROHMANN, M. Z.; RAMOS, M. S. Competências docentes como antecedentes da avaliação de desempenho do professor: percepção de mestrandos de administração. Avaliação, Campinas, v. 17, n. 1, p. 65-86, 2012.

HORTALE, V. A.; MOREIRA, C. O. F.; BOCHNER, R.; LEAL, M. do C. Trajetória profissional de egressos de cursos de doutorado nas áreas da saúde e biociências. Revista de Saúde Pública, São Paulo, v. 48, n. 1, p. 1-9, 2014.

LEITE FILHO, G. A.; MARTINS, G. de A. Relação orientador-orientando e suas influências na elaboração de teses e dissertações. RAE - Revista de Administração de Empresas, São Paulo, v. 46, número especial, p. 99-109, 2006.

LIMA, V. B. F.; ALENCAR, E. M. L. S. de. Criatividade em programas de pós-graduação em educação: práticas pedagógicas e fatores inibidores. Psico-USF, Itatiba, v. 19, n. 1, p. 61-72, 2014.

JOAQUIM, N. de F.; BOAS, A. A. V.; CARRIERI, A. de P. Estágio docente: formação profissional, preparação para o ensino ou docência em caráter precário? Educação e Pesquisa, São Paulo, v. 39, n. 2, p. 351-365, 2013.

JOAQUIM, N. de F.; VILAS BOAS, A. A.; CARRIERI, A. de P. Entre o discurso praticado e a realidade percebida no processo de formação docente. Avaliação, Campinas, v.17, n.2, p. 503-528, 2012.

KORNIS, G. E. M.; MAIA, L. S.; FORTUNA, R. F. P. A produção intelectual em Saúde Coletiva no âmbito do Estado do Rio de Janeiro: uma trajetória de 1960 a 2007. Physis, Rio de Janeiro, v. 20, n. 3, p. 913-929, 2010. 
LOUZADA, R. de C. R.; SILVA FILHO, J. F. da. Formação do pesquisador e sofrimento mental: um estudo de caso. Psicologia em Estudo, Maringá, v. 10, n. 3, p. 451-461, 2005.

LOUZADA, R. de C. R.; SILVA FILHO, J. F. da. Pós-graduação e trabalho: um estudo sobre projetos e expectativas de doutorandos brasileiros. História Ciências Saúde-Manguinhos, Rio de Janeiro, v. 12, n. 2, p. 265-282, 2005.

MATTOS, V. de B. Pós-graduação em tempos de precarização do trabalho. Alongamento da Escolaridade e Alternativa ao Desemprego. São Paulo: Xamã, 2011.

MENDES, A. L. T. M. et al. Curso de mestrado da Escola Anna Nery 19721975: singularidades da formação e desafios na implantação. Escola Anna Nery, Rio de Janeiro, v. 19, n. 1, p. 11-17, 2015.

MENDES, V. da R.; IORA, J. A. A opinião dos estudantes sobre as exigências da produção na pós-graduação. Revista Brasileira de Ciências do Esporte, Porto Alegre, v. 36, n. 1, p. 171-187, 2014.

MINAYO, M. C. S.; SANCHES, O. Quantitativo-Qualitativo: Oposição ou Complementaridade? Cadernos de Saúde Pública, Rio de Janeiro, v. 9, n. 3, p. 239-262, jul./set. 1993.

MOREIRA, E. C.; TOJAL, J. B. A. G. Prioridades dos programas de pós-graduação stricto sensu em Educação Física: a visão dos egressos. Revista Brasileira de Ciência do Esporte, Porto Alegre, v. 35, n. 1, p. 161-178, 2013.

NOVAES MALAGRIS, L. et al. Niveis de estresse e características sociobiográficas de alunos de pós-graduação. Psicologia em Revista, Belo Horizonte, v. 15, n. 2, p. 184-203, 2009.

OLIVEIRA, N.; SIQUEIRA, H. C. H. de. Mestrado acadêmico em enfermagem: interfaces de sua criação na perspectiva ecossistêmica. Escola Anna Nery, Rio de Janeiro, v. 17, n. 1, p. 73-81, 2013. 
ORTIGOZA, S. A. G.; POLTRONIERI, L. C.; MACHADO, L. M. C. P. A atuação profissional dos egressos como importante dimensão no processo de avaliação de programas de pós-graduação. Sociedade \& Natureza, Uberlândia, v. 24, n. 2, p. 243-254, 2012.

PARDO, M. B. L.; COLNAGO, N. A. S. Formação do pesquisador: resultados de cursos de pós-graduação em educação. Paidéia, Ribeirão Preto, v. 21, n. 49, p. 237-246, 2013.

PIMENTEL, R. G. “E agora, José?": jovens psicólogos recém-formados no processo de inserção no mercado de trabalho. (Dissertação de Mestrado)- Programa de Pós-Graduação em Psicologia, Universidade Federal de Santa Catarina, Florianópolis, 2007.

RAMOS, F. R. S. et al. Formação de mestres em enfermagem na Universidade Federal de Santa Catarina: contribuições sob a ótica de egressos. Revista Brasileira de Enfermagem, Brasília, v. 63, n. 3, p. 359$365,2010$.

REGO, A. et al. Os motivos de sucesso, afiliação e poder: perfis motivacionais de estudantes de graduação e pós-graduação e sua relação com níveis remuneratórios. Psicologia: Reflexão e Crítica, Porto Alegre, v. 18, n. 2, p. 225-236, 2005.

RIBEIRO, M. L.; CUNHA, M. I. da. Trajetórias da docência universitária em um programa de pós-graduação em Saúde Coletiva. Interface, Botucatu, v. 14, n. 32, p. 52-68, 2010.

SANTOS, A. F.; ALVES JUNIOR, A. Estresse e estratégias de enfrentamento em mestrandos de ciências da saúde. Psicologia: Reflexão e Crítica, Porto Alegre, v. 20, n. 1, p. 104-113, 2007.

SCHILLINGS, A. Processo de estresse em mestrandos. 2005. (Dissertação de Mestrado)-Programa de Pós-Graduação em Psicologia, Universidade Federal de Santa Catarina, Florianópolis, 2005.

SCHWARTZMAN, S. Nota Sobre a Transição Necessária da Pós-Graduação Brasileira. In: BRASIL. Plano Nacional de Pós-Graduação - PNPG 20112020. Brasília: Capes, 2010. p.34-52. 
SECAF, V.; KURCGANT, P. Doutores e doutorandos em enfermagem: motivos do mestrado em outras áreas. Revista Latino-Americana de Enfermagem, Ribeirão Preto, v. 7, n. 1, p. 5-10, 1999.

SILVA, M. M. da. Redes de relações sociais e acesso ao emprego entre os jovens: o discurso da meritocracia em questão. Educ. Soc., Campinas, v. 31, n. 110, p. 243-260, jan./mar. 2010.

SOUZA, L. K. de C. S. de.; PRADO, S. D.; FERREIRA, F. R.; CARVALHO, M. C. da V. S. C. "Eu queria aprender a ser docente": sobre a formação de mestres nos programas de pós-graduação do campo da Alimentação e Nutrição no Brasil. Revista de Nutrição, Campinas, v. 27, n. 6, p 725734, 2014.

TEIXEIRA, M. A. P. et al. Produção Científica em Orientação Profissional: Uma análise da Revista Brasileira de Orientação Profissional. Revista Brasileira de Orientação Profissional, São Paulo, v. 8, n. 2, p. 25-40, 2007.

TOURINHO, M. M.; PALHA, M. das D. C. A Capes, a universidade e a alienação gestada na pós-graduação. Cadernos EBAPE.BR, Rio de Janeiro, v. 12, n. 2, p. 270-283, 2014.

VILLARDI, B. Q.; VERGARA, S. C. Implicações da aprendizagem experiencial e da reflexão pública para o ensino de pesquisa qualitativa e a formação de mestres em administração. Revista de Administração Contemporânea, Curitiba, v. 15, n. 5, p. 794-814, 2011.

ZAIDAN, S. et al. Pós-Graduação, saberes e formação docente: uma análise das repercussões dos cursos de mestrado e doutorado na prática pedagógica de egressos do Programa de Pós-Graduação da Faculdade de Educação da UFMG (1977-2006). Educação em Revista, Belo Horizonte, v. 27, n. 1, p. 129-160, 2011. 